\title{
BMJ Open Descriptive epidemiology of changes in weight and weight-related behaviours of Australian children aged 5 years: two population-based cross-sectional studies in 2010 and 2015
}

\author{
Louise L Hardy, ${ }^{1,2}$ Louise A Baur, ${ }^{1,2,3}$ Li Ming Wen, ${ }^{2,3,4}$ Sarah P Garnett, ${ }^{2,5}$ \\ Seema Mihrshahi ${ }^{1,2,3}$
}

To cite: Hardy LL, Baur LA, Wen LM, et al. Descriptive epidemiology of changes in weight and weight-related behaviours of Australian children aged 5 years: two populationbased cross-sectional studies in 2010 and 2015. BMJ Open 2018;8:e019391. doi:10.1136/ bmjopen-2017-019391

- Prepublication history for this paper is available online. To view these files, please visit the journal online (http://dx.doi. org/10.1136/bmjopen-2017019391).

Received 30 August 2017 Revised 25 January 2018 Accepted 27 February 2018

Check for updates

For numbered affiliations see end of article.

Correspondence to

Dr Louise L Hardy;

louise.hardy@sydney.edu.au

\section{ABSTRACT}

Objective Over the past 10-15 years there has been substantial investment in New South Wales (NSW), Australia, to reduce child obesity through interventions in children aged $0-5$ years. We report changes in weight and weight-related behaviours of 5-year-old children.

Design Cross-sectional surveys conducted in 2010 and 2015.

Setting NSW schools $(2010 n=44 ; 2015 n=41)$ Participants Australian children in kindergarten (2010 $n=1141$ and $2015 n=1150$ ).

Outcome measures Change in anthropometry and indicators of diet, screen time, school travel and awareness of health recommendations. Additionally, we examined 2015 differences in weight-related behaviours by sociodemographic characteristics.

Results Prevalence of overweight/obesity was 2.1\% lower (adjusted OR (AOR) 0.83, 95\% Cl 0.67 to 1.04) and abdominal obesity $1.7 \%$ higher (AOR 1.35, 95\% Cl 0.93 to 1.98 ) in 2015 than 2010 . Significant improvements in multiple weight-related behaviours were observed among children in the highest tertile of junk food consumption (AOR $0.63,95 \% \mathrm{Cl} 0.50$ to 0.80 ), rewarded for good behaviour with sweets (AOR $0.59,95 \% \mathrm{Cl} 0.47$ to 0.74 ) and had a TV in their bedroom (AOR 0.65, 95\% $\mathrm{Cl} 0.43$ to 0.96 ). In 2015, children from low socioeconomic neighbourhoods and non-English-speaking backgrounds were generally less likely to engage in healthy weightrelated behaviours than children from high socioeconomic status neighbourhoods and from English-speaking backgrounds. Children in these demographic groups were less likely to eat breakfast daily, have high junk food intake and eat fast food regularly. Children from rural areas tended to have healthier weight-related behaviours than children from urban areas.

Conclusions There were significant positive changes in 5-year-old children's weight-related behaviours but children from low socioeconomic neighbourhoods and from non-English-speaking backgrounds were more likely to engage in unhealthy weight-related behaviours than children from high socioeconomic neighbourhoods and English-speaking backgrounds. The findings indicate that there is a need to enhance population-level efforts and
Strengths and limitations of this study

- Data come from two cross-sectional state population health surveys with high response rates, measured anthropometry and validated measures of weight-related behaviours.

- Although there is no international consensus for dietary cut points which has led to considerable variation across studies, our cut points were based on dietary guidelines to represent a lower frequency or 'limiting' consumption of discretionary foods.

- Parents completed the questionnaire and may be influenced by social desirability bias given the increasing role of social media in shaping community perceptions and public discourse on obesity.

ensure community programmes are targeted and tailored to meet different subpopulation needs.

\section{INTRODUCTION}

Children who are obese during childhood are five times more likely to be obese in adulthood compared with non-obese children. ${ }^{1}$ The evidence also shows that obesity-related behaviours including poor diet quality, decreased physical activity, increased sedentary behaviours and decreased sleep duration are established in, and tracked from, early childhood. ${ }^{2}$ Together, these findings suggest investment to promote healthy lifestyle behaviours during childhood may play a particularly strategic role in population obesity prevention.

Within a socioecological framework, the home environment exerts the most significant influence on children's acquisition of weight-related behaviours; however, as children grow the early child care setting also has an important role in the development 
of young children's weight-related behaviours. In 2014, in New South Wales (NSW), Australia, about 21\% of $<2$-year-olds, $58 \%$ of 2-3year-olds and $44 \%$ of $4-5$ yearolds attended some form of formal child care services, ${ }^{3}$ showing that these services are pivotal in reaching large numbers of children and their parents.

Over the past 10-15 years there has been substantial investment in NSW to reduce child obesity through a succession of state plans, policies and programmes to support the healthy development of children from birth to 5 years. The overarching strategy is a whole of government framework to encourage and support opportunities for the community to be healthy through the delivery of evidence-based, interactive and relevant programmes. These initiatives include professional development programmes for the early child care sector, ${ }^{4}$ supported playgroups, ${ }^{5}$ websites (eg, www.healthykids.nsw.gov.au), health screening programmes for 4 -year-olds ${ }^{6}$ and telephone-based support services for parents of children aged $0-2$ years. To date, a summary of the net effects of investment in early childhood obesity prevention in NSW is yet to be examined.

There is clear evidence that the distribution of child obesity is unequal across population groups. The population distribution of child obesity is higher among children from lower socioeconomic background status, internationally ${ }^{7}$ and in Australia. ${ }^{8}$ Similarly, the prevalence of child obesity can be higher among children from culturally and linguistically diverse (CALD) communities. In 2016, almost half of the Australian population were born overseas or have at least one parent born overseas and $21 \%$ speak a language other than English at home. ${ }^{9}$ Language spoken at home is a recognised indicator of CALD background and people who speak a non-English language at home tend to be recent immigrants who may be disadvantaged in health literacy and healthcare access. ${ }^{11}{ }^{11}$ These reasons underpin the importance of examining health outcomes by subpopulation groups to identify whether there are any apparent or emerging health inequalities among children from disadvantaged backgrounds.

The purpose of this study was to use cross-sectional surveillance data collected in 2010 and 2015 to examine changes in weight and weight-related behaviours of children in the first year of school. The assumption is that changes in the weight and weight-related behaviours of children entering school reflect the overall investment in early childhood by different stakeholders through multiple programmes and in different settings. We also examined weight-related behaviours by sociodemographic characteristics to identify subpopulations of children who may require greater support to change weight-related behaviours.

\section{METHODS}

Data come from the 2010 and 2015 NSW Schools Physical Activity and Nutrition Survey, a representative cross-sectional population survey of weight and weight-related behaviours of children aged 5-16 years conducted every 5 years. This study examined only data from children in kindergarten aged approximately 5 years. Detailed descriptions of the survey methodology are published elsewhere. ${ }^{12}$ Briefly, the surveys are designed to be representative of school-age children in terms of type of school, residence and socioeconomic status (SES). Sample size was based on detecting a difference of $10 \%$ in the prevalence of overweight/obesity between boys and girls within each year group, with $80 \%$ power and alpha $=0.05$. The surveys are school based and use comparable sampling frames that are based on a two-stage probability sample (school and student). The probability of school selection was proportional to size of the school enrolment. Schools were sampled from each education sector (government, independent, Catholic) proportional to enrolment in that sector and all students from two randomly selected classes were invited to participate. The study protocols were comparable for each survey year and data were collected in schools by trained field teams during February to April of each survey year. Informed consent from each child's parent/carer was a requirement for participation.

\section{Measures}

The questionnaire and measurement protocol were the same for both survey years. Parents completed the self-administered questionnaire for their child at home at time of consent. Sociodemographic information included the child's sex, date of birth, language spoken most often at home and postcode of residence. Postcode of residence was used as proxy measure of SES using the Australian Bureau of Statistics' Socio-Economic Indexes for Areas (SEIFA) Index of Relative Socio-economic Disadvantage. ${ }^{13}$ SEIFA scores from the 2011 census were used to rank students into low, middle and high SES neighbourhoods. Postcode of residence was also used to determine residential locality using the Accessibility/Remoteness Index of Australia in 2010 and the Australian Statistical Geography Standard in 2015, ${ }^{14}$ and children were categorised as living in urban or rural areas. Language spoken most often at home was used to categorise children into English-speaking or non-English-speaking backgrounds. ${ }^{15}$

Height $(\mathrm{m})$, weight $(\mathrm{kg})$ and waist circumference $(\mathrm{cm})$ were measured over one layer of light clothing during the school visit by field staff. Body mass index (BMI) was calculated $\left(\mathrm{kg} / \mathrm{m}^{2}\right)$ and children categorised as thin, healthy weight, overweight and obese using the International Obesity Task Force age-sex adjusted cut points. ${ }^{16}$ Waist-toheight ratio (WtHR), an indicator of abdominal obesity, was calculated as waist circumference $(\mathrm{cm})$ divided by height $(\mathrm{cm})$ and dichotomised as $<0.5$ or $\geq 0.5 .{ }^{17}$

Indicators of dietary intake were collected using a validated short food frequency questionnaire specifically developed for population surveillance surveys. ${ }^{18}$ Parents reported the usual frequency their child consumed fruits and vegetables (Doesn't eat fruits/vegetables, $<1$ serve/day, 1 serve/day, 2 serves/day, 3 serves/day, 
4 serves/day, 5 serves/day, 6 or more serves/day), and fried potato products, salty snack foods, snack foods, confectionery and ice cream (never/rarely, 1-2 times/ week, 3-4 times/week, 5-6 times/week, 1 time/day, 2 times/day). For the analysis, fruit and vegetable intakes were dichotomised according to daily recommended serves for children aged 5 years. ${ }^{19}$ Discretionary foods (ie, fried potato products, salty snack foods, snack foods, confectionery, ice cream) are not necessary for a healthy diet and the guidelines recommend limiting these foods. ${ }^{19}$ For the analysis, 'limited' was defined a priori as less than three times a week and discretionary foods were dichotomised as $<3$ or $\geq 3$ times/week. Additionally, because discretionary foods are rarely eaten in isolation we examined total consumption using a junk food intake measure. ${ }^{20}$

Information on eating behaviours included the frequency of eating breakfast, eating dinner in front of the TV and eating meals or snacks from fast-food outlets (never/rarely, <1/week, 1-2 times/week, 3-4 times/week, 5-6 times/week or every day). For the analysis, breakfast was dichotomised according to dietary guidelines as daily or not daily. ${ }^{19}$ There is no consensus how often children should eat dinner in front of the TV or eat fast foods; however, other research indicates that eating dinner in front of the TV five or more times/week is associated with poor diet quality and overweight in children, ${ }^{21}$ hence eating dinner in front of the TV was dichotomised as $<5$ or $\geq 5$ times/week. Eating fast foods one or more times a week is associated with increased BMI in children, ${ }^{22}$ so we dichotomised fast food as $<1$ (infrequent) or $\geq 1$ time/ week (frequent). Parents also reported how often they offered sweets to their child for good behaviour (rarely/ never, sometimes or usually) and these were dichotomised for the analysis as rarely/never or sometimes/ usually, based on dietary guidelines which recommend limiting discretionary foods.

Information about the home screen environment (TV, videos/DVDs, computer, smartphone, tablets, e-games) included whether their child had a TV in the bedroom (yes or no) and limiting their child's screen time (rarely/ never, sometimes or usually), and these were dichotomised for the analysis as rarely/never or sometimes/ usually. Time spent on screen devices was collected by questionnaire $^{23}$ and time dichotomised for the analysis according to screen time recommendations: $<2$ hours/ day or $\geq 2$ hours / day. ${ }^{24}$

Parents reported how their child usually travelled to and from school separately for each school day; options included walk, cycle, skateboard or scooter, car, bus, train or ferry/boat. Parents could report more than one travel mode for each trip. For the analysis, children's travel modes were classified as 'inactive travelers' if driven to and from school 5 days/week and 'active travelers' if they walked, cycled and used a skateboard or scooter to travel to and from school 5 days/week. Children who used multiple transport modes to travel to and from school were classified as 'mixed travelers'. Because active travel is considered a healthy behaviour and sitting time in car travel is considered less healthy, we only examined children who were active or inactive travellers.

Parents' awareness of national recommendations for children's physical activity and screen time was assessed by two questions: How many minutes of physical activity is it recommended that school-age children do each day? and Up to how many hours of television, video, DVD or computer games is it recommended that school-age children watch each day? The response options were to report the time or check 'Don't know'. Parents who reported the correct times were deemed to know the recommendations and parents who reported the incorrect time or 'don't know' were classified as not knowing the recommendation. Information on the child's physical activity was collected only in 2015 using a single-item question recommended for estimating physical activity in child surveys. The question was Over the past 7 days, on how many days was your child engaged in moderate to vigorous physical activity for at least $60 \mathrm{~min}$ ? Response categories were $0-7$ days, with a response of 7 days indication meeting the physical activity recommendations.

\section{Statistical analyses}

Data were analysed in June 2017 using SPSS Complex Sample Analysis (V.22 for Windows; IBM) to account for the complex sampling design. Poststratification weights were calculated to account for variations in response rates, along with cluster and stratification variables to account for the complex sampling design and weighted prevalences are presented. Missing values were not replaced ( $<5 \%$ of data). Categorical differences between 2010 and 2015 were first assessed using $X^{2}$ statistic, and analysis of variance was used for continuous variables. Logistic models were used to assess change between survey periods in weight outcomes, dietary patterns and habits, screen time, school travel and parent's awareness of national recommendations for physical activity and screen time. Covariates included sex, age, residence, SES tertile and language background.

Policy and decision makers require up-to-date evidence to guide the development of intervention and health promotion activities. Given the established evidence on sociodemographic differences among children's weight and weight-related behaviours, we report outcomes from the most recent survey (2015) to identify whether subgroups of children may require greater or more targeted intervention. We examined differences between children from rural and urban residences, low and high SES neighbourhoods, and from non-English-speaking backgrounds and English-speaking backgrounds using logistic regression, controlling for sex. We present the ORs and their corresponding 95\% CIs for each independent variable. The significance level was set at $\mathrm{p} \leq 0.05$.

\section{RESULTS}

The 2010 survey comprised 1141 children in kindergarten from 44 schools (response rate 62\%) and the 2015 survey 
Table 1 Sociodemographic characteristics of children by survey year ${ }^{\star}(\% ; 95 \% \mathrm{Cl})$

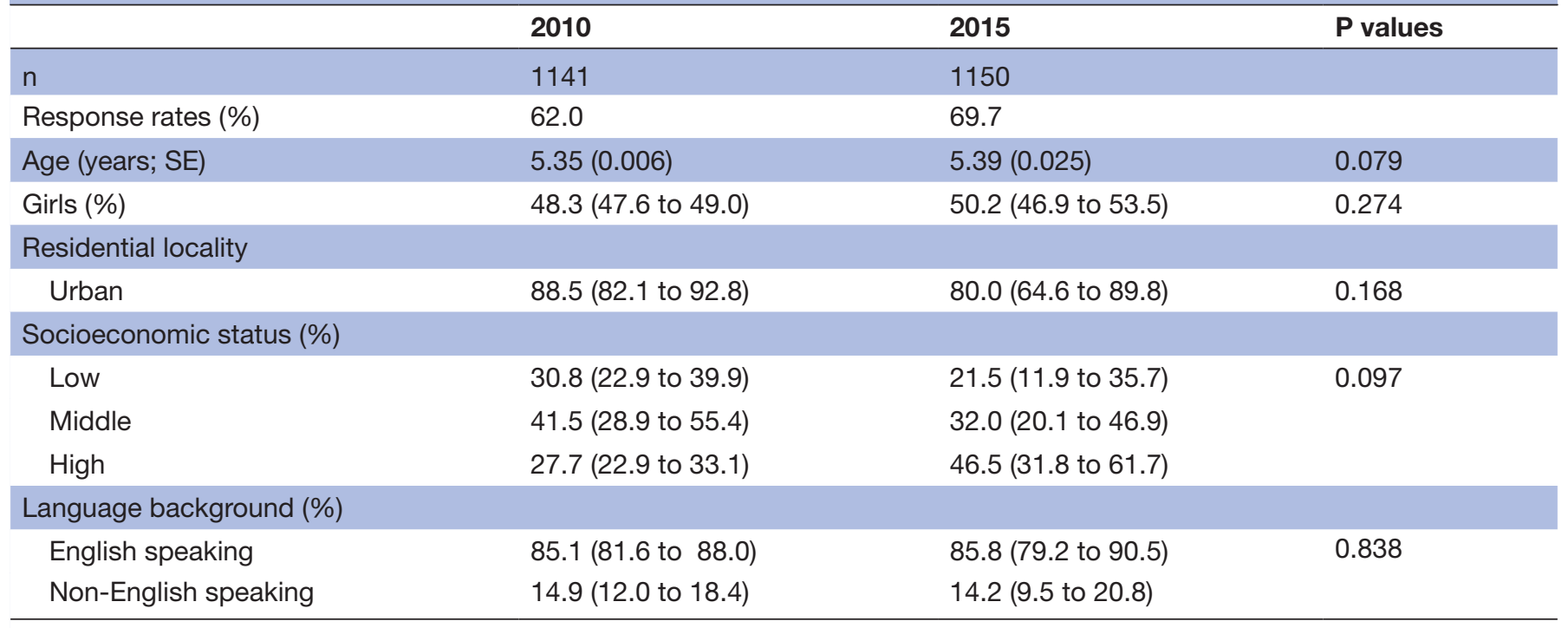

*Weighted percentages.

comprised 1150 children in kindergarten from 41 schools (response rate $70 \%$ ). Table 1 shows there were no significant differences in the children's sociodemographic characteristics between surveys. At both surveys, the majority of children were from English-speaking backgrounds and resided in urban areas. The prevalence and adjusted ORs of overweight, obesity, overweight-obesity combined and $\mathrm{WtHR} \geq 0.5$, stratified by sex are presented in table 2 and show there were no statistically significant changes between survey years. In 2015, approximately one in six children were overweight/obese and had WtHR $\geq 0.5$.

Table 3 shows there were some significant positive changes in behaviours including the lower consumption of junk food, less TVs in children's bedrooms and a higher parental awareness of children's screen time and physical activity recommendations. Although changes were not

Table 2 Prevalence and change between 2010 and 2015 of overweight, obesity and waist-to-height ratio and adjusted OR (AOR; $95 \% \mathrm{Cl})^{*}$

\begin{tabular}{|c|c|c|c|c|}
\hline & \multicolumn{2}{|c|}{ Survey year } & \multirow{2}{*}{$\begin{array}{l}\text { Change (\%) } \\
(2010-2015)\end{array}$} & \multirow{2}{*}{$\begin{array}{l}\text { AOR } \\
(2010=\text { reference group }\end{array}$} \\
\hline & 2010 & 2015 & & \\
\hline All children $(n) \dagger$ & 1141 & 1150 & & \\
\hline Obese (\%) & 5.7 & 6.3 & 0.6 & 1.49 (0.83 to 2.68$)$ \\
\hline Overweight/obese (\%) & 19.6 & 17.5 & -2.1 & 0.83 (0.67 to 1.04$)$ \\
\hline Girls (n)‡ & 551 & 577 & & \\
\hline Overweight (\%) & 15.6 & 12.6 & -3.0 & $0.83(0.60$ to 1.14$)$ \\
\hline Obese (\%) & 6.4 & 6.6 & 0.2 & 1.41 (0.83 to 2.40$)$ \\
\hline Overweight/obese (\%) & 22.0 & 19.2 & -2.8 & 0.98 (0.73 to 1.33$)$ \\
\hline WtHR $\geq 0.5$ & 16.7 & 18.1 & 1.4 & 1.30 (0.83 to 2.03$)$ \\
\hline Obese (\%) & 5.0 & 6.1 & 1.1 & 1.77 (0.77 to 4.07$)$ \\
\hline Overweight/obese (\%) & 17.3 & 15.7 & -1.6 & 1.11 (0.64 to 1.93$)$ \\
\hline WtHR $\geq 0.5$ & 13.1 & 14.8 & 1.7 & 1.51 (0.98 to 2.32$)$ \\
\hline
\end{tabular}

*Weighted prevalences.

†AOR, adjusted for age, sex, residence, SES and language background. $\ddagger A O R$, adjusted for age, residence, SES and language background.

AOR, adjusted OR; SES, socioeconomic status; WtHR, waist-to-height ratio.

Bolded values are statistically significant. 
Table 3 Prevalence of children's weight-related behaviours, by survey year $(\%, 95 \% \mathrm{Cl})^{*}$

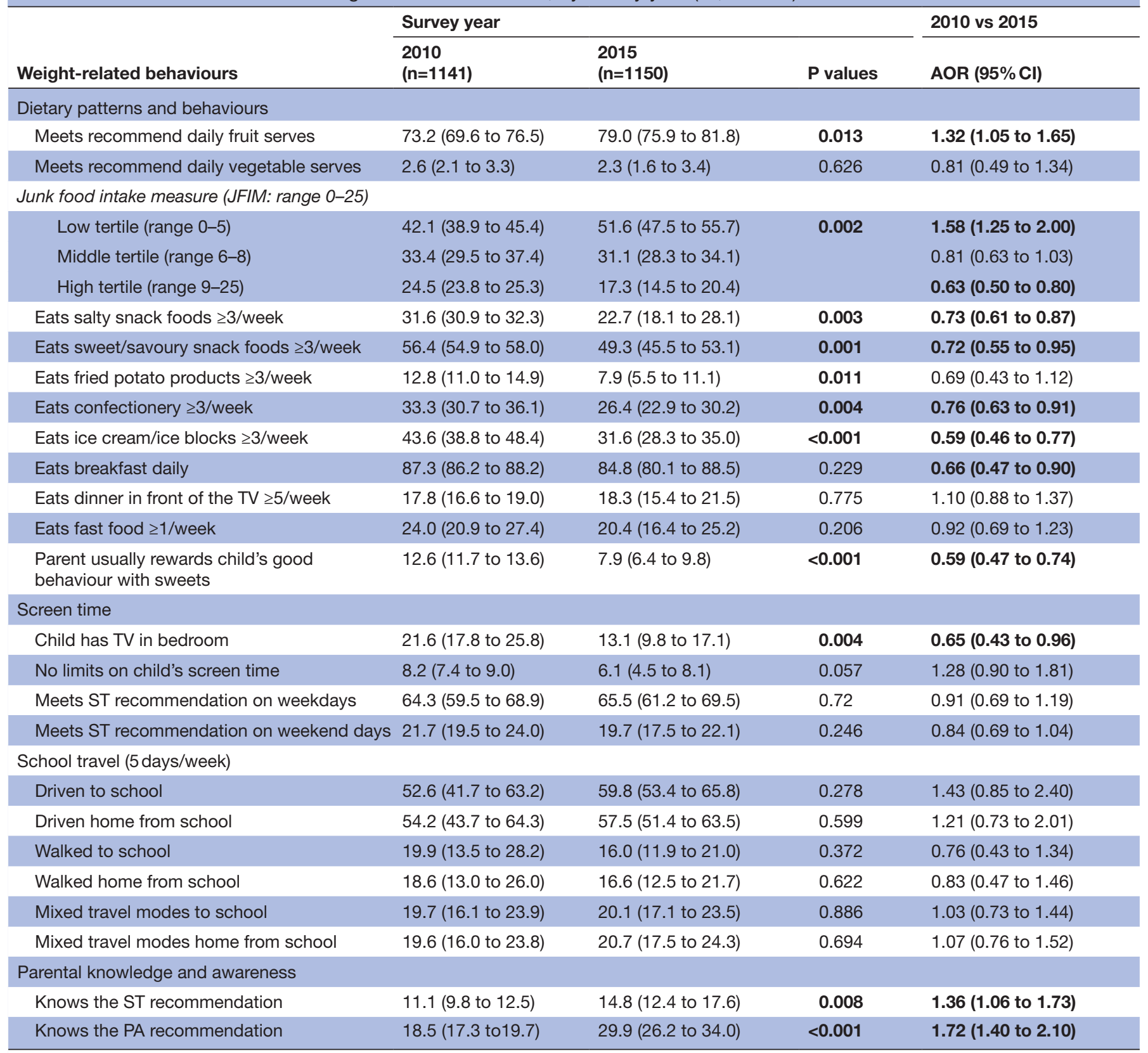

*Weighted prevalences.

Covariates include sex, residence, SES tertile and language background.

AOR, adjusted OR; PA, physical activity; SES, socioeconomic status; ST, screen time.

Bolded values are statistically significant.

statistically significant, the daily consumption of vegetables remained low, with less than 3\% of children meeting the recommendation; $15 \%$ of children did not eat breakfast daily, one in five children regularly ate dinner in front of the TV and ate fast food one or more times a week. Parental awareness of the screen time recommendation increased between surveys, yet one-third of children did not meet the recommendation on school days and four in five did not meet the recommendation on weekend days. There were no changes in children's school travel.

Table 4 shows the OR, adjusted for sex, for unhealthy weight-related behaviours by sociodemographic characteristics in 2015. Children residing in urban areas were less likely to meet recommended daily serves of vegetables, eat breakfast daily and to regularly eat dinner in front of the TV than children living in rural areas. Compared with children from high SES neighbourhoods, children in low SES neighbourhoods were generally more than twice as likely to have a high junk food intake, not eat breakfast daily, eat fast food one or more times a week, have a TV in the bedroom, not meet screen time recommendations on weekdays and be driven to and from school daily. 


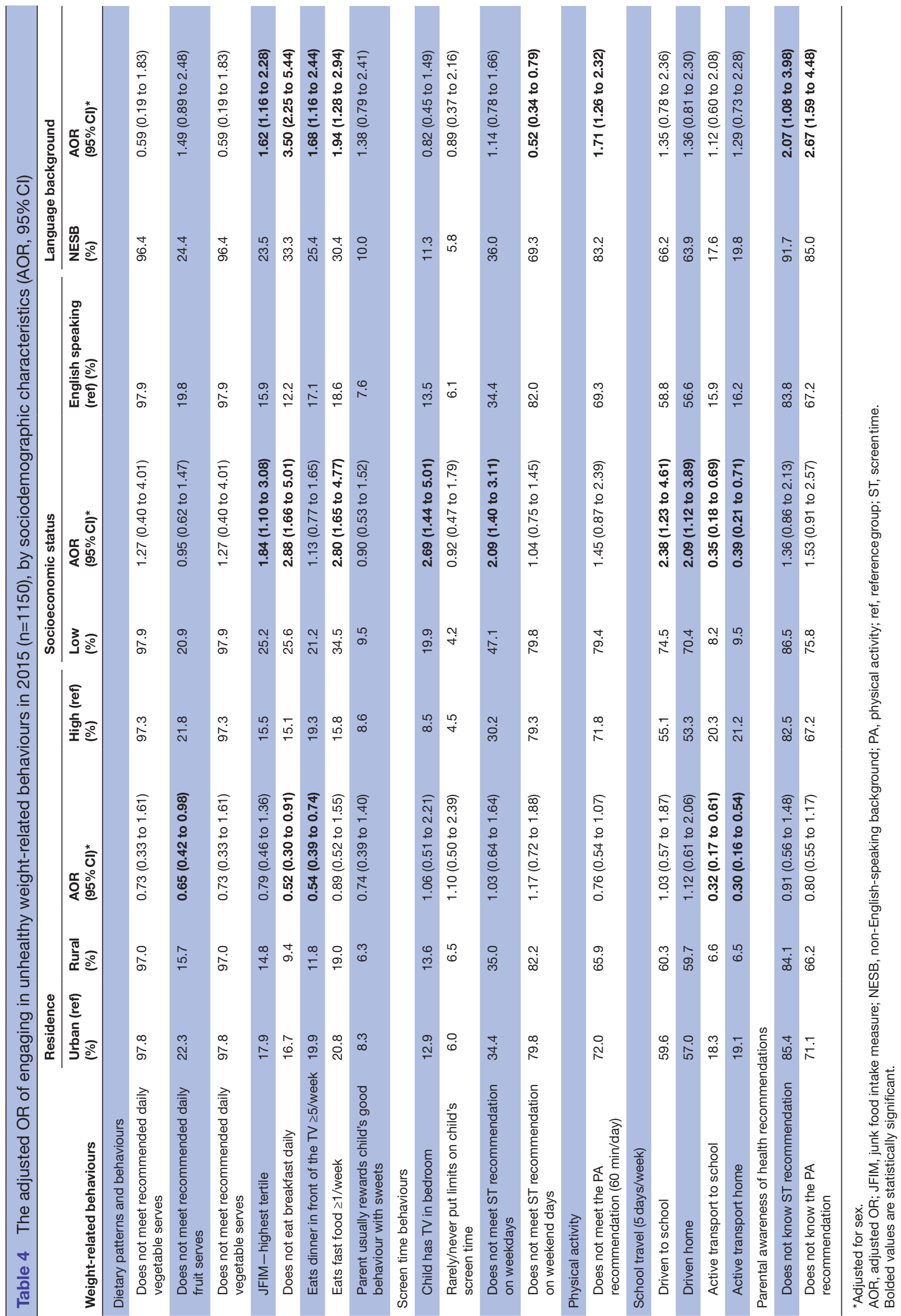

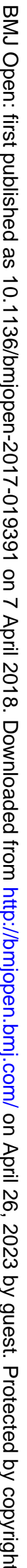


Children from non-English-speaking backgrounds were more likely to have higher junk food consumption, not eat breakfast daily, regularly eat dinner in front of the TV and eat fast food one or more times a week than children from English-speaking backgrounds. Parents from non-English-speaking backgrounds were more than twice as likely to not know the daily recommendations for screen time and physical activity than parents from English-speaking backgrounds. Compared with children from English-speaking backgrounds, those from non-English-speaking backgrounds were less likely to not meet screen time recommendations on weekend days.

\section{DISCUSSION}

This study shows there have been significant, positive changes in weight-related behaviours of 5-year-old children between 2010 and 2015 and, although not statistically significant, the prevalences of overweight and overweight-obesity were lower in 2015 than 2010. The higher, but not statistically significant, prevalences of obesity and WtHR $\geq 0.5$ in 2015 may indicate that the degree of obesity is increasing. That is, the distribution of BMI is shifting to the right and the prevalence of morbid obesity among children may be increasing; a finding previously reported among Australian children. ${ }^{25}$ Although based on cross-sectional data, the sample is representative of the children of NSW and these findings are promising. Understanding the drivers for the changes we observed is difficult because of the complex interacting contexts of obesity prevention. There may well be factors that were not measured such as genetic susceptibility and environmental features such as the food and physical activity environments, which may also be influencing the prevalence. In NSW, there has been substantial investment in population obesity prevention since $2002^{26-29}$ and potentially, the changes we observed in some behaviours reflect a compounding effect of continual and multiple investments over the past 10-15 years, so that the children who participated in the 2015 survey will have had greater opportunity to be exposed to obesity prevention programmes, compared with the children we measured in 2010. However, because of our cross-sectional design no causal relationships can be ascertained, so it cannot be determined whether deficiencies in the type/content of the programme or in uptake of the programme are the reason for the results.

While there were positive changes in many weight-related behaviours, the prevalence of some behaviours in 2015 remains a concern. The most notable is the very low proportion of children (2.3\%) meeting the recommended intake of vegetables, indicating these children are missing the benefits of dietary vitamins, minerals and fibre. ${ }^{19}$ This finding is consistent with national surveys ${ }^{30}$ and other studies which have shown vegetable intake in Australian children is poor. ${ }^{31}$ Conversely, $79 \%$ of children met recommended intake of fruit, but adherence was lower among children living in urban areas than children living in rural areas. Potentially, national schoolbased fruit and vegetable programmes ${ }^{32}$ need to focus on promoting vegetables.

Children's consumption of discretionary or 'junk' foods was lower in 2015 than 2010 but the consumption of these foods remains higher than dietary guidelines recommend. Our findings are consistent with national data which estimate that more than one-third of energy intake among children aged 4-8 years comes from discretionary foods. ${ }^{33}$ In 2015, the consumption of discretionary foods was higher among children living in low SES neighbourhoods and children from non-English-speaking backgrounds than their peers. A recent systematic review ${ }^{34}$ concluded that fast-food outlets were more prevalent in low than middle and high SES neighbourhoods, and in areas with high concentrations of ethnic minority groups; however, further qualitative work is required to determine if factors other than availability influence consumption. Potential promising strategies to reduce children's junk food consumption include limiting the accessibility, availability and advertising of these foods to young children, increasing food literacy among parents, and working with the food industry to improve nutrient profiles of junk foods. ${ }^{35}$

Home-based eating practices associated with overweight/obesity in children include eating breakfast daily, eating dinner in front of the TV, eating snacks/meals from fast-food and take-away outlets and parents rewarding children's good behaviour with sweets. ${ }^{36}$ Eating a healthy breakfast daily (eg, whole grains, fresh fruits/vegetables) has been linked to a decreased risk in obesity, ${ }^{37}$ better nutrient intakes ${ }^{38}$ and improved school attendance, which in turn may improve academic outcomes in schoolchildren, ${ }^{39}$ yet one in seven children in this study did not eat breakfast daily and those children were more likely to live in urban areas, have low SES neighbourhoods and be from non-English-speaking backgrounds.

Parental use of sweets as rewards may adversely impact on children's diet through reinforcing a child's preference and liking for sweet food rewards. ${ }^{40}$ We found the proportion of parents using sweets as a reward for good behaviour was significantly lower in 2015 which may influence caloric intake and the development of dental caries. Parents can inadvertently promote excess weight gain in childhood through role modelling food routines such as eating in front of the TV and regular consumption of fast foods that establish these behaviours as normal eating routines. One in five children in this study frequently ate in front of the TV and this practice was more prevalent among children living in urban areas and from non-English-speaking backgrounds. We have no information on the quality of the dinners that were eaten in front of the TV; however, other studies suggest children's food choices deteriorated with increased frequency of eating in front of the TV. ${ }^{41}$ Qualitative research is required to understand cultural differences in this practice which can then inform health promotion efforts to encourage meals to be eaten without the TV on or other screen devices 
at a table. Consumption of fast food was twofold higher among children from low SES neighbourhoods and non-English-speaking cultural backgrounds, compared with their high SES and English-speaking peers. We did not collect information on the type of fast food eaten but a recent review showed that fast-food outlets are more concentrated in lower income neighbourhoods. ${ }^{42}$ Hence, efforts to reduce fast-food consumption need to consider town planning and regulations on the placement of fastfood outlets in communities.

Australia recommends limiting screen time among 5 -year-old children to $<2$ hours/day, ${ }^{24}$ yet less than one in seven parents in this study knew this recommendation in 2015. Therefore, it is not surprising that one-third of children did not meet the recommendation on weekdays, increasing to four in five children on weekend days. Internationally, children's adherence to the screen time recommendation is low, ${ }^{43}$ leading to debate on whether the 2-hour limit is relevant, or whether parents need assistance to adhere to the recommendation. Fewer children had a TV in the bedroom in 2015 which may reduce excessive exposure to unhealthy food advertising that targets children $^{41}$; however, we were unable to ascertain if TVs were replaced with other screen devices. Ascertaining the use of LED screen devices at bedtime is important given the potential deleterious effects on children's melatonin which is associated with harmful effects on children's sleep and well-being. ${ }^{44}$

Ideally, children should accrue at least $60 \mathrm{~min}$ of moderate to vigorous physical activity daily, ${ }^{24}$ but in 2015 less than one-third of parents knew the recommendation, and awareness was low among parents from non-English-speaking backgrounds. Active school transport is an opportunity to increase children's daily physical activity; however, three in five children were driven to/from school and the prevalence of passive school transport was twofold higher among children from low SES neighbourhoods than children from high SES neighbourhoods. We were unable to determine why children from low SES neighbourhoods were more likely to be driven to school; however, there is a range of factors which may influence young children's active school travel, including distance, parent (and child's) perception of heavy traffic, pedestrian infrastructure, connectivity and family time constraints. ${ }^{45}$ These factors may have greater influence on children's active school transport in low SES neighbourhoods; however, Australia is increasingly becoming a car-dependent country which may influence school commuting. ${ }^{46}$

Key strengths of our study include the large representative sample, high response rates and validated measures of weight-related behaviours, but there are limitations to consider. This study was a secondary analysis of two population-based surveys. The sample sizes were not large enough to detect a smaller difference in the prevalence of overweight/obesity. For example, to detect $1 \%$ or $2 \%$ change that is of public health significance at a population level would require a much larger sample size. Our sampling frames were representative of NSW children in terms of type of school, residence and SES, so the findings may not necessarily be generalisable to all Australian children. Survey response rates are often considered an indicator of survey quality, yet there is no scientific consensus on a minimal threshold. Response rates $>60 \%$ are considered acceptable; however, the representativeness of the sample is potentially of more importance. ${ }^{47}$ At age 5 years, children cannot reliably respond to a questionnaire, so parents are viewed as an appropriate alternative. The accuracy of proxy reporting is not known, but parents are potentially more strongly affected by social desirability bias which may have influenced our findings particularly given the rise in information about child obesity and the increasing role of social media in shaping community perceptions and public discourse on obesity. ${ }^{48}$ Similarly, the potential for non-responder bias raises the issue of whether population surveillance surveys which benefit public health should have passive rather than active consent. The lack of international consensus regarding dietary cut points has led to considerable variation across studies and our cut points were based on dietary guidelines to represent a lower frequency or 'limiting' consumption of discretionary foods. Finally, it was not feasible to objectively measure physical activity and while the validated single-item question we used to assess children's physical activity is recommended for population surveys it prohibited contextual detail on type and duration of physical activities.

\section{CONCLUSIONS}

Our findings suggest there have been positive changes in the weight-related behaviours of children entering their first year of school following years of child obesity prevention investment. Establishing healthy behaviours in preschool-age children may offset the challenges of changing established unhealthy behaviours in older children and adolescents. It is not possible to attribute the findings to one intervention; rather the changes reflect the sum of the many obesity prevention activities. These 5-year-old children have had exposure to a range of obesity prevention programmes, including statewide interventions to up-skill the early childhood sector workforce in the delivery of healthy eating and physical activity activities. We showed that greater investment is required among families living in low SES neighbourhoods and areas with high concentrations of families from non-English-speaking backgrounds to reduce health inequalities in these children. Qualitative research will assist with determining the needs of families with less social and economic advantage which can then be adapted to the current intervention frameworks so that interventions are targeted and tailored to meet different subpopulation needs.

Author affiliations

${ }^{1}$ Prevention Research Collaboration, Sydney School of Public Health, The University of Sydney, Sydney, New South Wales, Australia 
${ }^{2}$ Sydney Medical School, The University of Sydney, Sydney, New South Wales, Australia

${ }^{3}$ NHMRC Centre for Research Excellence in The Early Prevention of Obesity in Childhood, The University of Sydney, Sydney, New South Wales, Australia ${ }^{4}$ Health Promotion Unit, Sydney Local Health District, Camperdown, NSW, Australia ${ }^{5}$ Institute of Endocrinology and Diabetes, Kids Research Institute at the Children's Hospital, Westmead, New South Wales, Australia

Contributors LLH, LAB, SPG, LMW and SM had equal contributions to this paper. LLH led the writing and conducted the data analysis. LLH had full access to all of the data (including statistical reports and tables) in the study and can take full responsibility for the overall content.

Funding NSW Ministry of Health

Competing interests None declared.

Patient consent Parental/guardian consent obtained.

Ethics approval University of Sydney Human Research Ethics Committee, the NSW Department of Education and Training, and the NSW Catholic Education Commission.

Provenance and peer review Not commissioned; externally peer reviewed.

Data sharing statement The data that support the findings of this study are available from NSW Ministry of Health but restrictions apply to the availability of these data, which were used under licence for the current study, and so are not publicly available. Data are however available from the authors upon reasonable request and with permission of NSW Ministry of Health.

Open Access This is an Open Access article distributed in accordance with the Creative Commons Attribution Non Commercial (CC BY-NC 4.0) license, which permits others to distribute, remix, adapt, build upon this work non-commercially, and license their derivative works on different terms, provided the original work is properly cited and the use is non-commercial. See: http://creativecommons.org/ licenses/by-nc/4.0/

(c) Article author(s) (or their employer(s) unless otherwise stated in the text of the article) 2018. All rights reserved. No commercial use is permitted unless otherwise expressly granted.

\section{REFERENCES}

1. Simmonds M, Llewellyn A, Owen CG, et al. Predicting adult obesity from childhood obesity: a systematic review and meta-analysis. Obes Rev 2016;17:95-107.

2. Larson N, Ward DS, Neelon SB, et al. What role can child-care settings play in obesity prevention? A review of the evidence and call for research efforts. J Am Diet Assoc 2011;111:1343-62.

3. Australian Bureau of Statistics. Childhood Education and Care, Australia. Canberra: Australian Bureau of Statistics, 2014.

4. Farrell L, King L, Hardy LL, et al. Munch and move in preschools. Summary report on implementation and evaluation, phase 1 (2008 -2009). Sydney: Prevention Research Collaboration, University of Sydney, 2009.

5. Weber D, Rissel C, Hector D, et al. Supported playgroups as a setting for promoting physical activity of young children: findings from a feasibility study in south-west Sydney, Australia. J Paediatr Child Health 2014;50:301-5.

6. Robinson A, Denney-Wilson E, Laws R, et al. Child obesity prevention in primary health care: investigating practice nurse roles, attitudes and current practices. J Paediatr Child Health 2013;49:E294-E99.

7. Wang Y, Lim H. The global childhood obesity epidemic and the association between socio-economic status and childhood obesity. Int Rev Psychiatry 2012;24:176-88.

8. Hardy LL, Mihrshahi S, Gale J, et al. 30-year trends in overweight, obesity and waist-to-height ratio by socioeconomic status in Australian children, 1985 to 2015. Int J Obes 2017;41:76-82.

9. Australian Bureau of Statistics. Cultural diversity in Australia, 2016. Canberra: Australian Bureau of Statistics, 2017.

10. IOM (Institute of Medicine). Race, Ethnicity, and Language Data: standardization for health care quality improvement. Washington, DC: The National Academies Press, 2009.

11. Ou L, Chen J, Hillman K. Health services utilisation disparities between English speaking and non-English speaking background Australian infants. BMC Public Health 2010;10:182.
12. Hardy LL, Mihrshahi S, Drayton BA, et al. Methods: NSW Schools Physical Activity and Nutrition Survey (SPANS) 2015; full report. Sydney: NSW Ministry of Health, 2017:46-58.

13. Australian Bureau of Statistics. Census of Population and Housing: Socio-Economic Indexes for Areas (SEIFA), Australia - data only, 2011. 2013. Catno 2033055001. http://www.abs.gov.au/AUSSTATS/ abs@.nsf/DetailsPage/2033.0.55.0012006?OpenDocument (accessed 13 Mar 2015).

14. Australian Bureau of Statistics. Australian Statistical Geography Standard (ASGS)- Remoteness structure, Canberra. 2013.

15. Australian Bureau of Statistics. Australian Standard Classification of Languages (ASCL). 2nd Edn. Canberra: Australian Bureau of Statistics, 2011.

16. Cole TJ, Lobstein T. Extended international (IOTF) body mass index cut-offs for thinness, overweight and obesity. Pediatr Obes 2012;7:284-94.

17. Brambilla P, Bedogni G, Heo M, et al. Waist circumference-to-height ratio predicts adiposity better than body mass index in children and adolescents. Int J Obes 2013;37:943-6.

18. Flood VM, Wen LM, Hardy LL, et al. Reliability and validity of a short FFQ for assessing the dietary habits of 2-5-year-old children, Sydney, Australia. Public Health Nutr 2014;17:498-509.

19. National Health and Medical Research Council. Australian dietary guidelines. Canberra: National Health and Medical Research Council, 2013.

20. Boylan S, Hardy LL, Drayton BA, et al. Assessing junk food consumption among Australian children: trends and associated characteristics from a cross-sectional study. BMC Public Health 2017:17:299-99.

21. Liang T, Kuhle S, Veugelers PJ. Nutrition and body weights of Canadian children watching television and eating while watching television. Public Health Nutr 2009;12:2457.

22. Braithwaite I, Stewart AW, Hancox RJ, et al. Fast-food consumption and body mass index in children and adolescents: an international cross-sectional study. BMJ Open 2014;4:e005813.

23. Hardy LL, Booth ML, Okely AD. The reliability of the Adolescent Sedentary Activity Questionnaire (ASAQ). Prev Med 2007;45:71-4.

24. Department of Health. Australia's Physical activity and sedentary behaviour quidelines for children (5-12 years). Canberra: Commonwealth of Australia, 2014.

25. Garnett SP, Baur LA, Jones AM, et al. Trends in the prevalence of morbid and severe obesity in Australian Children Aged 7-15 Years, 1985-2012. PLoS One 2016;11:e0154879.

26. NSW Ministry of Health. NSW Healthy eating and active living strategy: preventing overweight and obesity in New South Wales 2013-2018. Sydney: NSW Ministry of Health, 2013.

27. NSW Department of Health. NSW Government plan for preventing overweight and obesity in children, young people \& their families 2009 - 2011. Sydney: NSW Department of Health, 2009.

28. NSW Government. NSW Making it Happen. Secondary NSW Making it Happen: premier's priorities. 2016. https://www.nsw.gov.au/ making-it-happen

29. NSW Health. NSW Child Obesity Summit CommitteeNSW Childhood Obesity Summit Draft Program. In: ed. Sydney: NSW Department of Health, 2002.

30. Australian Bureau of Statistics. National Health Survey: first results, 2014-15 - Australia. Canberra: Commonwealth of Australia, 2015.

31. Whitrow MJ, Moran L, Davies MJ, et al. Core food intakes of Australian children aged 9-10 years: nutrients, daily servings and diet quality in a community cross-sectional sample. J Hum Nutr Diet 2016;29:449-57.

32. Association HK. Crunch\&Sip, Secondary Crunch\&Sip. http://www. healthy-kids.com.au/category/8/crunch-sip

33. Australian Bureau of Statistics. Australian Health Survey: nutrition first results - foods and nutrients, 2011-12 - Australia. Canberra: Commonwealth of Australia, 2015.

34. Fleischhacker SE, Evenson KR, Rodriguez DA, et al. A systematic review of fast food access studies. Obes Rev 2011;12:e460-71.

35. Hawkes C, Smith TG, Jewell J, et al. Smart food policies for obesity prevention. Lancet 2015;385:2410-21.

36. MacFarlane A, Cleland V, Crawford D, et al. Longitudinal examination of the family food environment and weight status among children. Int $J$ Pediatr Obes 2009;4:343-52.

37. Vik FN, Te Velde SJ, Van Lippevelde W, et al. Regular family breakfast was associated with children's overweight and parental education: Results from the ENERGY cross-sectional study. Prev Med 2016:91:197-203.

38. Barr SI, DiFrancesco L, Fulgoni VL. Breakfast consumption is positively associated with nutrient adequacy in Canadian children and adolescents. Br J Nutr 2014;112:1373-83. 
39. Anzman-Frasca S, Djang HC, Halmo MM, et al. Estimating impacts of a breakfast in the classroom program on school outcomes. JAMA Pediatr 2015;169:71-7.

40. Skouteris $\mathrm{H}, \mathrm{McC}$ abe M, Swinburn B, et al. Parental influence and obesity prevention in pre-schoolers: a systematic review of interventions. Obes Rev 2011;12:315-28.

41. Boyland EJ, Halford JC. Television advertising and branding. Effects on eating behaviour and food preferences in children. Appetite 2013;62:236-41.

42. Fraser LK, Edwards KL, Cade J, et al. The geography of fast food outlets: a review. Int J Environ Res Public Health 2010;7:2290-308.

43. Arundell L, Fletcher E, Salmon J, et al. A systematic review of the prevalence of sedentary behavior during the after-school period among children aged 5-18 years. Int J Behav Nutr Phys Act 2016;13:93.
44. Hale L, Guan S. Screen time and sleep among school-aged children and adolescents: a systematic literature review. Sleep Med Rev 2015;21:50-8.

45. Pont K, Ziviani J, Wadley D, et al. Environmental correlates of children's active transportation: a systematic literature review. Health Place 2009;15:849-62.

46. van der Ploeg HP, Merom D, Corpuz G, et al. Trends in Australian children traveling to school 1971-2003: burning petrol or carbohydrates? Prev Med 2008;46.

47. Johnson TP, Wislar JS. Response rates and nonresponse errors in surveys. JAMA 2012;307:1805-6.

48. Chou WY, Prestin A, Kunath S. Obesity in social media: a mixed methods analysis. Transl Behav Med 2014;4:314-23. 